\title{
Grinding Force of 42CrMo Steel in Grind-Hardening
}

\author{
Gui-Cheng WANG ${ }^{1,2,}$, Jun-Feng ZOU ${ }^{1, b}$, Tian-Cheng HUANG $^{1, c}$, \\ Hong-Jie PEl ${ }^{2, d^{*}}$ \\ 'Nantong Institute of Technology, Nantong, Jiangsu, 226002 P. R. China \\ 2 School of Mechanical Engineering, Jiangsu University, Zhenjiang, Jiangsu, 212013 P.R. China \\ awgch@ujs.edu.cn, bjfzou@yeah.net, chuangtc2000@163.com, dhjpei@ujs.edu.cn
}

"Corresponding author

\begin{abstract}
Keywords: Grind-Hardening, Grinding Speed, Grinding Depth, Workpiece Speed, 42CrMo steel, , Ratio of Grinding Force
\end{abstract}

\begin{abstract}
Grinding force has important effects on the forming and quality of the hardened layer. The grind-hardening test of $42 \mathrm{CrMo}$ steel was carried out on a forming grinding machine. The results show the chief influence factor on the tangential and normal grinding force is the grinding depth, the grinding speed takes the second place and the workpiece speed is the last. When the grinding depth and workpiece speed increases, the tangential grinding force and normal grinding force both increase. The tangential grinding force and normal grinding force are declining as the grinding speed increasing. The results also show the chief influence factor on the ratio of the tangential and normal grinding force is the grinding depth, and the workpiece speed takes the second place and the grinding speed is the last. With the increase of the grinding speed and grinding depth, the grinding ratio increases. However, with the increase of the workpiece speed, the grinding ratio decreases. It provides the foundation for improving the quality of the grind-hardening.
\end{abstract}

\section{Introduction}

The grind-hardening is a new production process utilizing grinding heat effects, coupling with mechanical effects to induce the surface hardening directly for no hardened steel. It combines grinding and surface quenching within one step, reducing the investments of thermal treatment equipment and people. It also reduces the environment pollution from emission, so it has remarkable economic and social benefit [1].In 1994 Brinksmeier advocated the new technology of grind-hardening. Since then, many scholars both here and abroad did more research on $40 \mathrm{Cr}$ steel, 45 steel, 60 steel and $65 \mathrm{Mn}$ steel and had made a series of achievements[1-6].So far, little research has been done about the research on the characteristics and influence factors of grinding force of 42CrMo Steel in grind-hardening [7-8]. Grinding force in grind-hardening has important influence on the workpiece surface integrity and the quality of the hardened layer [7]. Therefore, based on the orthogonal surface grind-hardening test of $42 \mathrm{CrMo}$ steel, the change trend of grinding force and ratio of grinding force was analyzed, and the influence of the grinding parameter on the grinding force and the ratio of grinding force were studied.

\section{Experimental Condition and Measurement Method}

The test sample material is the quenched-tempered steel of the $42 \mathrm{CrMo}$ and the size is $170 \mathrm{~mm} \times 100 \mathrm{~mm} \times 25 \mathrm{~mm}$. Table 1 indicates the chemical composition of $42 \mathrm{CrMo}$ steel. The grind-hardening test was carried on the surface grinder of MKL7132X6/12. The grinding force was measured in the process of grind-hardening by the three-way piezoelectric dynamometer of Kistler9257B. The grind-hardening test conditions are as shown in Table 2. The orthogonal test has three influence factors including: the grinding speed $v_{s}$, the grinding depth $a_{p}$ and the workpiece speed $v_{w}$ designated A, B, C respectively. The orthogonal test scheme is given in Table 3 . The test platform of grind-hardening is as shown in Fig.1. 


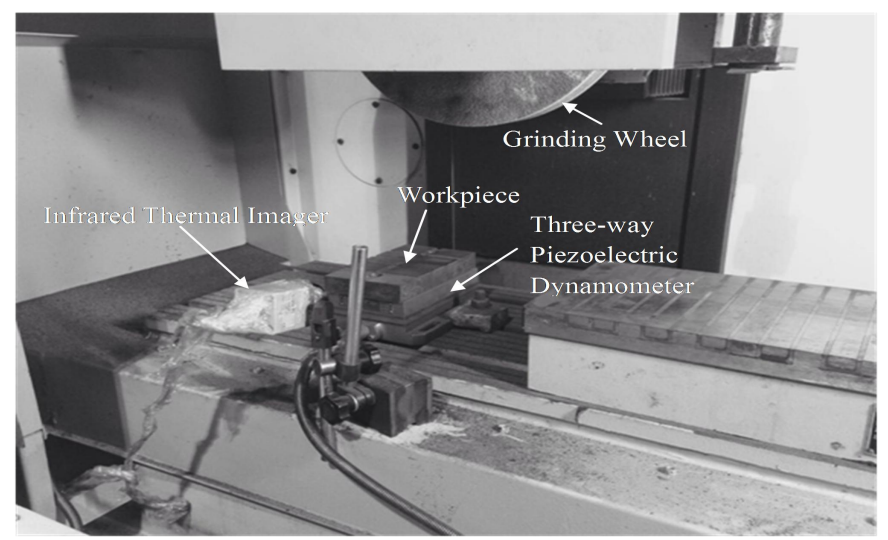

Fig.1 Test platform of grind-hardening

Tab.1 Chemical composition of 42CrMo steel (wt $\%)$

\begin{tabular}{|l|l|l|l|l|l|l|}
\hline $\mathrm{C}$ & $\mathrm{Si}$ & $\mathrm{Mn}$ & $\mathrm{Cr}$ & $\mathrm{Mo}$ & $\mathrm{S}$ & $\mathrm{P}$ \\
\hline $0.38-0.45$ & $0.17-0.37$ & $0.5-0.8$ & $0.9-1.2$ & $0.15-0.25$ & $\leq 0.035$ & $\leq 0.035$ \\
\hline
\end{tabular}

Tab.2 Orthogonal Test Parameters

\begin{tabular}{|l|l|}
\hline Original structure & Quenched and tempered state \\
\hline Grinding wheel specification and model & P400×40×127 WA60L6V \\
\hline Grinding speed $v_{s}(\mathrm{~m} / \mathrm{s})$ & $20,25,30,35$ \\
\hline Grinding depth $a_{p}(\mathrm{~mm})$ & $0.1,0.2,0.3,0.4$ \\
\hline Workpiece speed $v_{w}(\mathrm{~m} / \mathrm{min})$ & $0.15,0.3,0.45,0.6$ \\
\hline Grinding mode & one-way down-grinding \\
\hline Cooling condition & dry \\
\hline
\end{tabular}

Tab.3 Orthogonal test scheme

\begin{tabular}{|l|l|l|l|l|}
\hline Number & $\begin{array}{c}\text { Grinding speed } \\
v_{s}(\mathrm{~m} / \mathrm{s})\end{array}$ & $\begin{array}{c}\text { Grinding depth } a_{p} \\
(\mathrm{~mm})\end{array}$ & $\begin{array}{c}\text { Workpiece speed } \\
v_{w}(\mathrm{~m} / \mathrm{min})\end{array}$ & $\begin{array}{c}\text { Wheel } \\
\text { speed } N(\mathrm{r} / \mathrm{min})\end{array}$ \\
\hline 1 & 20 & 0.1 & 0.15 & 954.9 \\
\hline 2 & 20 & 0.2 & 0.3 & 954.9 \\
\hline 3 & 20 & 0.3 & 0.45 & 954.9 \\
\hline 4 & 20 & 0.4 & 0.6 & 954.9 \\
\hline 5 & 25 & 0.1 & 0.3 & 1193.6 \\
\hline 6 & 25 & 0.2 & 0.15 & 1193.6 \\
\hline 7 & 25 & 0.3 & 0.6 & 1193.6 \\
\hline 8 & 25 & 0.4 & 0.45 & 1193.6 \\
\hline 9 & 30 & 0.1 & 0.45 & 1432.4 \\
\hline 10 & 30 & 0.2 & 0.6 & 1432.4 \\
\hline 11 & 30 & 0.3 & 0.15 & 1432.4 \\
\hline 12 & 30 & 0.4 & 0.3 & 1432.4 \\
\hline 13 & 35 & 0.1 & 0.6 & 1671.1 \\
\hline 14 & 35 & 0.2 & 0.45 & 1671.1 \\
\hline 15 & 35 & 0.3 & 0.3 & 1671.1 \\
\hline 16 & 35 & 0.4 & 0.15 & 1671.1 \\
\hline
\end{tabular}

In the test, the grinding force $\mathrm{Fx}, \mathrm{Fy}, \mathrm{Fz}$ are corresponding the tangential grinding force $\mathrm{Ft}$, the axial grinding force Fn and the normal grinding force Fn. Compared with Ft and Fn, Fa is very small and has 
no noticeable change. Therefore, the effects of grinding parameter on the tangential grinding force Ft and the normal grinding force Fn were discussed.

\section{Experimental Results and Discussion}

When the grinding speed $25 \mathrm{~m} / \mathrm{s}$, the grinding depth $0.4 \mathrm{~mm}$, the workpiece speed $0.45 \mathrm{~m} / \mathrm{min}$, the curve of tangential grinding force and normal grinding force are as shown in Fig.2 and Figure.3.As can be observed in Fig.2, the grinding process is divided into the beginning part, the steady state part and the ending part. In the process of the beginning part and the ending part, the varied range of grinding force is very big caused by the change of the material removal rate. The grinding wheel wear increasing, the increase of unbalanced beating caused by the shape of grinding wheel makes grinding force bigger and bigger with the process of grinding. In order to eliminate the effect of numerical symbols, take the numerical symbols of the stable region of the grinding force as the experimental value of grinding force.

The measured results of grinding force are all discrete values. The grinding force at the $i(i=1,2,3 \ldots n)$ moments of the statistical area can be supposed as $x_{i}$, then the grinding force under the condition of the experimental value can be obtained as shown in Eq.1. The measured results of grinding force at different conditions are given in Table 4 and Table 5.

$$
x_{r m s}=\sqrt{\frac{1}{N} \sum_{i=1}^{n} x_{i}^{2}}=\sqrt{\frac{x_{1}^{2}+x_{2}^{2}+\cdots+x_{n}^{2}}{N}}
$$

Where $x_{m s}$ is the mean square value of the grinding force of the statistical area, $\mathrm{N}$ is the number of the grinding force of the statistical area.

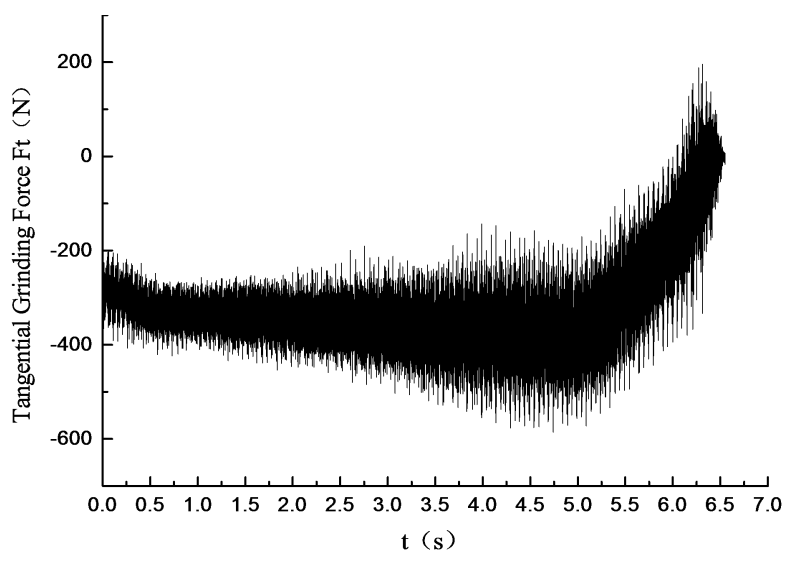

Fig.2 Measured curve of tangential grinding force

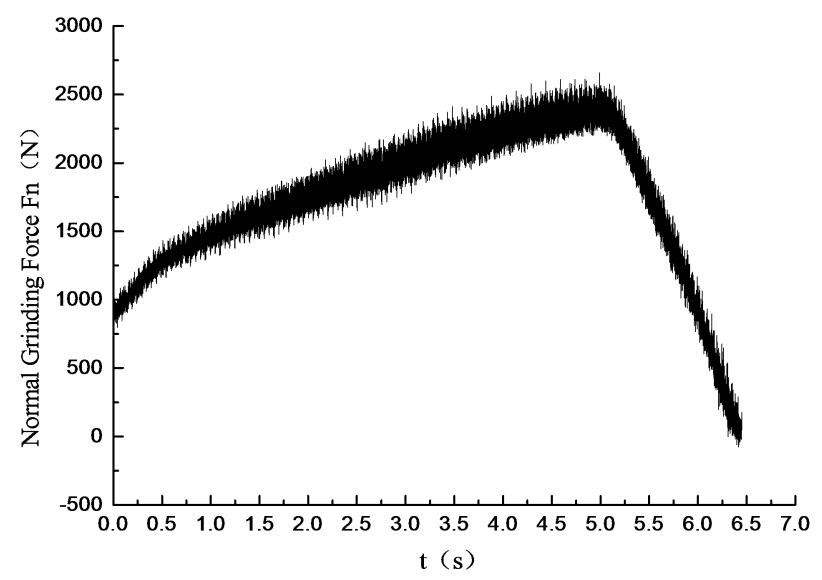

Fig.3 Measured curve of normal grinding force 


\section{Influence of Grinding Parameter on Tangential Grinding Force}

The visual analysis table of the measured tangential grinding force as shown in Tab. 4. It can be seen from Tab.4, the dominant influence factor on the tangential grinding force is the grinding depth, the grinding speed takes the second place and the workpiece speed is the last. It can be concluded from domino offect curves of the tangential grinding force in Fig.4,when grinding depth and workpiece speed increases, tangential grinding force increases, and the increasing trend becomes larger. The tangential grinding force is declining and decreasing trend becomes leveling off as the grinding speed increasing.

Tab.4 Visual analysis table of the tangential grinding force

\begin{tabular}{|c|c|c|c|c|}
\hline \multirow{2}{*}{ Number } & \multicolumn{3}{|c|}{ Horizontal Matrix } & \multirow[t]{2}{*}{ Tangential grinding force $\mathrm{Ft}(\mathrm{N})$} \\
\hline & $\mathrm{A}$ & $\mathrm{B}$ & $\mathrm{C}$ & \\
\hline 1 & 1 & 1 & 1 & 167.79 \\
\hline 2 & 1 & 2 & 2 & 241.35 \\
\hline 3 & 1 & 3 & 3 & 312.74 \\
\hline 4 & 1 & 4 & 4 & 522.01 \\
\hline 5 & 2 & 1 & 2 & 100.8 \\
\hline 6 & 2 & 2 & 1 & 179.44 \\
\hline 7 & 2 & 3 & 4 & 353.51 \\
\hline 8 & 2 & 4 & 3 & 373.47 \\
\hline 9 & 3 & 1 & 3 & 167.26 \\
\hline 10 & 3 & 2 & 4 & 156.09 \\
\hline 11 & 3 & 3 & 1 & 163.42 \\
\hline 12 & 3 & 4 & 2 & 249.66 \\
\hline 13 & 4 & 1 & 4 & 164.97 \\
\hline 14 & 4 & 2 & 3 & 154.61 \\
\hline 15 & 4 & 3 & 2 & 179.59 \\
\hline 16 & 4 & 4 & 1 & 180.12 \\
\hline Mean 1 & 310.972 & 150.205 & 172.692 & \\
\hline Mean 2 & 251.805 & 182.873 & 192.850 & \\
\hline Mean 3 & 184.107 & 252.315 & 252.020 & \\
\hline Mean 4 & 169.823 & 331.315 & 299.145 & \\
\hline Range & 141.149 & 181.110 & 126.453 & \\
\hline
\end{tabular}
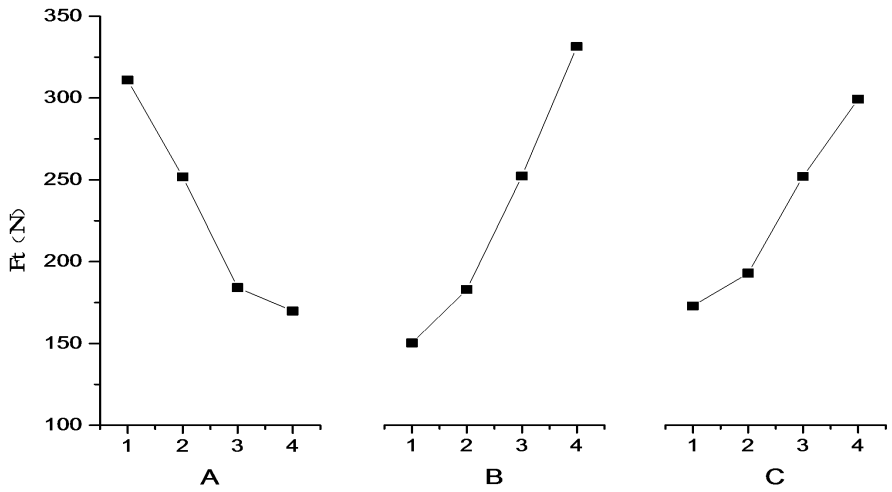

Fig.4 Domino offect curves of the tangential grinding force

\section{Influence of Grinding Parameter on Normal Grinding Force}

The visual analysis table of the measured normal grinding force as shown in Table 5. It can be seen from Table 5, the dominant influence factor on the normal grinding force is the grinding depth, the grinding speed takes the second place and the workpiece speed is the last. It can be concluded from domino offect 
curves of the normal grinding force in Fig.5, with the increase of the grinding depth, the normal grinding force increases. However, the overall trend of the normal grinding force becomes larger as the grinding speed decreasing and the workpiece speed increasing.

Tab.5 Visual analysis table of the normal grinding force

\begin{tabular}{|c|c|c|c|c|}
\hline \multirow{2}{*}{ Number } & \multicolumn{3}{|c|}{ Horizontal Matrix } & \multirow[t]{2}{*}{ Normal grinding force $\mathrm{Fn}(\mathrm{N})$} \\
\hline & $\mathrm{A}$ & $\mathrm{B}$ & $\mathrm{C}$ & \\
\hline 1 & 1 & 1 & 1 & 675.29 \\
\hline 2 & 1 & 2 & 2 & 901.46 \\
\hline 3 & 1 & 3 & 3 & 1050.69 \\
\hline 4 & 1 & 4 & 4 & 2288.80 \\
\hline 5 & 2 & 1 & 2 & 337.19 \\
\hline 6 & 2 & 2 & 1 & 827.19 \\
\hline 7 & 2 & 3 & 4 & 1661.19 \\
\hline 8 & 2 & 4 & 3 & 2205.57 \\
\hline 9 & 3 & 1 & 3 & 615.62 \\
\hline 10 & 3 & 2 & 4 & 424.57 \\
\hline 11 & 3 & 3 & 1 & 1223.49 \\
\hline 12 & 3 & 4 & 2 & 1843.37 \\
\hline 13 & 4 & 1 & 4 & 735.69 \\
\hline 14 & 4 & 2 & 3 & 612.01 \\
\hline 15 & 4 & 3 & 2 & 916.57 \\
\hline 16 & 4 & 4 & 1 & 1359.81 \\
\hline Mean 1 & 1229.060 & 590.947 & 1021.445 & \\
\hline Mean 2 & 1257.785 & 691.308 & 999.648 & \\
\hline Mean 3 & 1026.763 & 1212.985 & 1120.973 & \\
\hline Mean 4 & 906.020 & 1924.388 & 1277.563 & \\
\hline Range & 351.765 & 1333.441 & 277.915 & \\
\hline
\end{tabular}

It can be observed in the Fig.4 and Fig.5, with the increase of the grinding depth, the grinding force increases. This is because of the increase of the grinding depth, along with the average of un-deformed chip thickness of the single grit $\overline{a_{g}}$ increasing, the contact arc length of the workpiece-wheel will lengthen, which means the number of abrasive participating in cutting increases, so the grinding force increases. With the increase of the workpiece speed, the average of un-deformed chip thickness of the single grit $\bar{a}_{g}$ increasing, the grinding force increases. With the increase of the grinding speed, the number of abrasive participating in cutting in unit time increasing, the average of un-deformed chip thickness of the single grit $a_{g}$ decreases[6-7], so the grinding force will decrease.
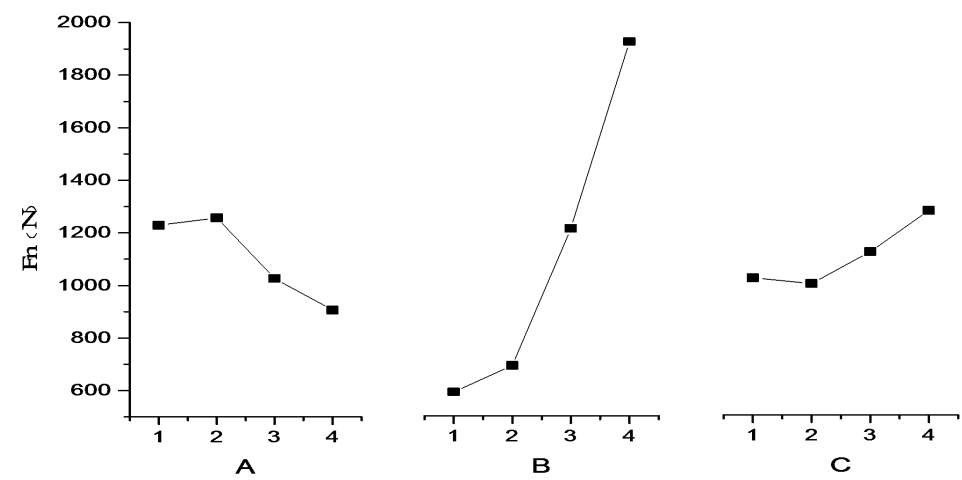

Fig.5 Domino offect curves of the normal grinding force 


\section{Influence of Grinding Parameter on the Ratio of Grinding Force}

The visual analysis table of the ratio of the grinding force as shown in Tab.6.In the conventional grinding, $\mathrm{Fn} / \mathrm{Ft}$ is in the range of 1.6 to1.8, while $\mathrm{Fn} / \mathrm{Ft}$ in the experiment is in the range of 2.7 to 7.6 . So it is in the range of the grinding force ratio in grind-hardening. It can be seen from table 6 , the chief influence factor on the ratio of the tangential and normal grinding force is the grinding depth, and the workpiece speed takes the second place and the grinding speed is the last. It can be concluded from domino offect curves of the normal grinding force in Fig.6, with the increase of the grinding speed and grinding depth, the grinding ratio increases. However, with the increase of the workpiece speed, the grinding ratio decreases.

Tab.6 Visual analysis table of the ratio of the grinding force

\begin{tabular}{|l|l|l|l|l|}
\hline \multirow{2}{*}{ Number } & \multicolumn{3}{|l|}{ Horizontal Matrix } & \multirow{2}{*}{$F_{n} / F_{t}$} \\
\cline { 2 - 4 } & A & B & C & 4.02 \\
\hline 1 & 1 & 1 & 1 & 3.73 \\
\hline 2 & 1 & 2 & 2 & 3.36 \\
\hline 3 & 1 & 3 & 3 & 4.38 \\
\hline 4 & 1 & 4 & 4 & 3.35 \\
\hline 5 & 2 & 1 & 2 & 4.61 \\
\hline 6 & 2 & 2 & 1 & 4.7 \\
\hline 7 & 2 & 3 & 4 & 5.91 \\
\hline 8 & 2 & 4 & 3 & 3.68 \\
\hline 9 & 3 & 1 & 3 & 2.72 \\
\hline 10 & 3 & 2 & 4 & 7.49 \\
\hline 11 & 3 & 3 & 1 & 7.38 \\
\hline 12 & 3 & 4 & 2 & 4.46 \\
\hline 13 & 4 & 1 & 4 & 3.96 \\
\hline 14 & 4 & 2 & 3 & 5.1 \\
\hline 15 & 4 & 3 & 2 & 7.55 \\
\hline 16 & 4 & 4 & 1 & \\
\hline Mean 1 & 3.872 & 3.877 & 5.917 & \\
\hline Mean 2 & 4.643 & 3.755 & 4.890 & \\
\hline Mean 3 & 5.317 & 5.162 & 4.228 & \\
\hline Mean 4 & 5.268 & 6.305 & 4.065 & \\
\hline Range & 1.445 & 2.550 & 1.852 & \\
\hline
\end{tabular}
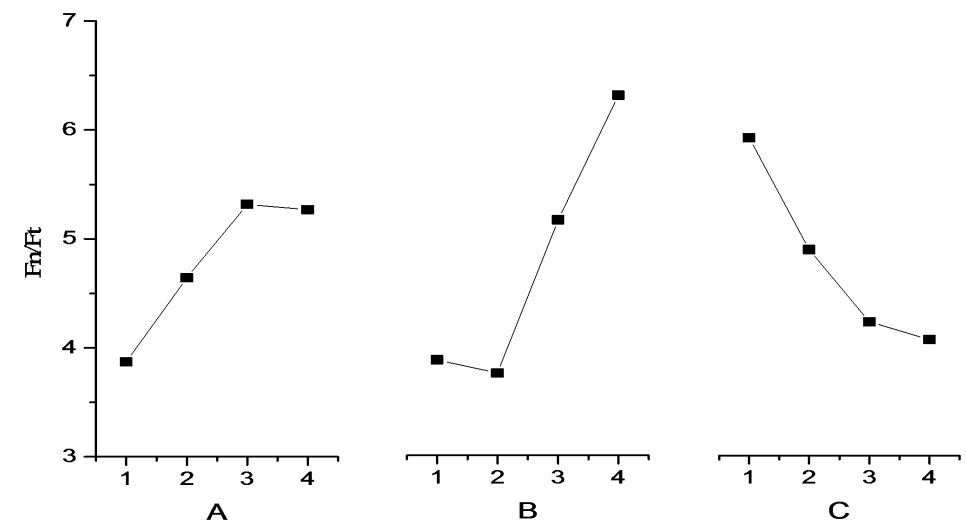

Fig.6 Domino effect curves of the ratio of the grinding force

In the grind-hardening, the grinding force consists of chip deformation force and friction force [9]. The average of un-deformed chip thickness of the single grit will increase with the increase of the grinding depth, so the normal chip deformation force Fnc and the tangential chip deformation force Ftc increase 
simultaneously. At the same time, friction coefficient of workpiece-wheel reduces because of the thermal softening in the hot environment [8]. The result is that the normal friction force Fns increases and the tangential friction force Fts decreases relativity. Therefore, the increase of the grinding depth leads to the increase of the grinding force ratio $\mathrm{Fn} / \mathrm{Ft}$.

\section{Summary}

1. The grinding process is divided into the beginning part, the steady state part and the ending part. In the process of the beginning part and the ending part, the varied range of grinding force is very big caused by the change of the material removal rate. The grinding wheel wear increasing, the increase of unbalanced beating caused by the shape of grinding wheel makes grinding force bigger and bigger with the process of grinding.

2. The chief influence factor on the tangential and normal grinding force is the grinding depth, the grinding speed takes the second place and the workpiece speed is the last. When the grinding depth and workpiece speed increases, the tangential grinding force and normal grinding force both increase. The tangential grinding force and normal grinding force are declining as the grinding speed increasing.

3. The chief influence factor on the ratio of the tangential and normal grinding force is the grinding depth, and the workpiece speed takes the second place and the grinding speed is the last. With the increase of the grinding speed and grinding depth, the grinding ratio increases. However, with the increase of the workpiece speed, the grinding ratio decreases.

\section{Acknowledgements}

This research is based upon work by the NNSF of China (Grant No.51075192), National key projects of P.R.China(Grant 2013ZX04009031) and Nantong key laboratory (CPI2014002).

\section{References}

[1] T.Brockhoff. Annals of the CIRP. 48(1999) 255- 260.

[2] I.Zarudi ,L.C. Zhang. J Mater Sci. 37(2002) 3935- 3943.

[3] D.C.Fricker,T. Pearce, A.Harrison .J Eng Manuf. 218(2004) 1339- 1356.

[4] G.Chryssolouris,K.Tsirbas, K.Salonitis. J Manuf Process.7(2005) 1- 9.

[5] T.Nguyen, I. Zarudi, L. C. Zhang. nt J Mach Tools Manuf. 47(2007) 97- 106.

[6] Ju-Dong LIU. Studies on the forming mechanism of the grinding-hardening and its application fundament [D]. Zhenjiang: Jiangsu University, 2005.( In Chinese)

[7] Ju-Dong LIU, Gui-Cheng WANG, Kang-Min CHEN. China J Mech Eng, 17 (2006) 1842-1845. (In Chinese)

[8] Song-Wei HUANG, Ju-Dong LIU. Tooling Engineering. 45(2011) 75-77. (In Chinese)

[9] Ke-Ming LIU, Zhuang MA, Lian-Yong ZHANG. Mater Mech Eng. 36(2012) 58-61. (In Chinese) 